University of Nebraska - Lincoln

DigitalCommons@University of Nebraska - Lincoln

Sociology Department, Faculty Publications

Sociology, Department of

2007

\title{
Adult Social Capital and Track Placement of Ethnic Groups in Germany
}

\author{
Simon Cheng \\ University of Connecticut \\ Leslie Martin \\ Boise State University \\ Regina E. Werum \\ Emory University, rwerum2@unl.edu
}

Follow this and additional works at: https://digitalcommons.unl.edu/sociologyfacpub

Part of the Family, Life Course, and Society Commons, and the Social Psychology and Interaction

Commons

Cheng, Simon; Martin, Leslie; and Werum, Regina E., "Adult Social Capital and Track Placement of Ethnic Groups in Germany" (2007). Sociology Department, Faculty Publications. 604.

https://digitalcommons.unl.edu/sociologyfacpub/604

This Article is brought to you for free and open access by the Sociology, Department of at DigitalCommons@University of Nebraska - Lincoln. It has been accepted for inclusion in Sociology Department, Faculty Publications by an authorized administrator of DigitalCommons@University of Nebraska - Lincoln. 


\title{
Adult Social Capital and Track Placement of Ethnic Groups in Germany
}

\author{
SIMON CHENG \\ University of Connecticut \\ LESLIE MARTIN \\ Boise State University \\ REGINA E. WERUM \\ Emory University
}

The dictum that "context matters" notwithstanding, few researchers have focused on how social capital affects educational outcomes for ethnic groups outside of the United States. Using German Socioeconomic Panel (GSOEP) data, analyses highlight the group-specific effects of parental social capital on track placement among 11-16-year-old German and non-German students. For both groups, parents' family ties fail to affect track placement. Parents' community ties have mixed effects. Among Germans, parental involvement in sports affects children's tracking positively. Among non-Germans, parental socializing with peers affects track placement negatively, while parental involvement in religion-based community groups and interethnic ties with Germans improve track placement chances. We relate these findings to different strands of social capital theory.

How does access to "social capital" affect educational outcomes? Drawing largely on Coleman's (1988) conceptualization, research has focused on the positive impact of triangular ties among parents, teachers, and children (Lareau 1987; Parcel and Dufur 2001; Stanton-Salazar and Dornbusch 1995; Stevenson and Baker 1987). Intragenerational peer networks among children have garnered similar attention, though the literature suggests that such ties may have a detrimental impact on achievement. While some studies point to the positive effects of contacts among adults (Carbonaro 1998), others find that parent involvement and social closure have group-specific, and sometimes even negative, effects on academic outcomes (Carter and Wojtkewicz 2000; Downey 1995; Kao 1995; Morgan and Sorensen 1999; Rumbaut 1997). More-

Electronically published August 22, 2007

American Journal of Education 114 (November 2007)

(C) 2007 by The University of Chicago. All rights reserved.

0195-6744/2007/11401-0002\$10.00 
over, social capital theorists have long debated the relative merits of "strong versus weak ties" (Granovetter 1983). This debate is central to Coleman's conceptualization, which stresses the importance of strong primary group ties (family, friends), as well as to Bourdieu's argument that community and organizationally based ties, however superficial they may be, carry the greatest potential (Frank et al. 2004; Goyette and Conchas 2002; Stanton-Salazar and Spina 2003).

The existing literature reveals three gaps. To date, most studies have focused on how social capital affects academic achievement in the United States. ${ }^{1} \mathrm{We}$ know little about whether or how social capital affects children's educational trajectories elsewhere because social networks and the organization of schooling (e.g., in Europe) differ greatly from those in the United States (Broaded 1997; Shavit and Blossfeld 1993; Shavit and Müller 1998). Second, researchers rarely have examined social capital's effect on other key educational outcomes, such as track placement. Track placement remains one of the single most important predictors of long-term occupational and social mobility in countries like Germany, and it has explicitly ethnic dimensions (Alba et al. 1994; Kristen 2002). Third, researchers rarely challenge the assumption that all forms of social capital have similar effects across ethnic groups (see Bankston 2004; and Kao 1995). In particular, class and ethnic dynamics shape parent-teacher interaction styles and the level of parental involvement (Lareau 1989; Lareau and Horvat 1999; Useem 1992). Questioning the assumption that social capital effects are universal helps improve our understanding of how social capital operates as a mechanism through which educational inequalities are reproduced.

Given the common emphasis on intrafamilial social capital dynamics (parent-child communication), we raise the empirical question whether parents' extrafamilial ties prove just as crucial for educational outcomes (Goyette and Conchas 2002; Wong 1998). Specifically, we examine the impact that adult ties to family and community (hereafter "parental social capital") have on the

SimON CHENG is assistant professor of sociology at the University of Connecticut. He is interested in race/ethnicity, education, family, and quantitative methodology. Recent publications in these areas appeared in American Fournal of Sociology, American Sociological Review, and Sociological Methods and Research. LESLIE MARTIN is assistant professor of sociology at Boise State University. In addition to her interest in educational policy and ethnic stratification, her research revolves around contemporary housing policy and political mobilization in the United States. Her work has recently been published in Urban Affairs Review. REGINA E. WERUM is associate professor of sociology at Emory University. Focusing on comparative historical and contemporary issues, she has published on secondary and higher educational policy, educational expansion, and stratification in the United States, the Caribbean, and Germany. 
track placement of German and non-German students. In the process, we draw on competing conceptualizations of social capital (Bourdieu 1979, 1980, 1986; Coleman 1988, 1990), treating adult ties as means toward an end (i.e., as proxies for the formation and activation of social capital resources). Assuming that information about the educational system benefits children's educational trajectories, we should expect parents' access to such information to come from other adults around them (Kao 2004), including institutional agents and informal mentors in the community (Stanton-Salazar and Dornbusch 1995; Stanton-Salazar and Spina 2003).

We address two questions: How does parental social capital affect children's track placement? And does it differentially affect the tracking experiences of Germans and non-Germans? Analyses are based on track placement patterns among secondary students and use sample data from several waves of the German Socioeconomic Panel (GSOEP). Our findings challenge the assumption, still held dear by many U.S. researchers, that the impact of family-based forms of social capital outweighs all others. Instead, findings point to the importance of extrafamilial and organizationally based ties, as well as the ethnicspecific pathways in which parental social capital shapes social reproduction.

\section{Background}

\section{How Does Social Capital Relate to Educational Outcomes?}

Theoretical background. - Competing social capital perspectives raise the question of whether optimal social capital formation and activation stems from intrafamilial or extrafamilial ties (including formal or organizationally rooted networks; Granovetter 1983; Lin 1999; Portes and Sensenbrenner 1993; Putnam 2000). ${ }^{2}$ Therefore, we examine which types of intrafamilial and community ties among adults shape children's track placement. In the process, we provide insights into how German versus ethnic minority families use their respective social capital to "navigate" an educational system with which they may or may not be familiar (Bankston and Zhou 1995; Kalmijn and Kraaykamp 1996; Teachman et al. 1997).

Despite efforts to link structure and agency, Coleman's (1987, 1988, 1990) work primarily focused on interpersonal ties and individual actors. When theorizing how social capital shapes educational outcomes, he suggested that it is multiphenomenal. Yet, "unlike other forms of capital, social capital inheres in the structure of relations between persons and among persons" (Coleman 1990, 302; Lin 1999; Portes 1998). Coleman distinguished several kinds of interpersonal ties (intrafamilial vs. extrafamilial and intergenerational vs. intragenerational), focusing on parent-child communication and parental in- 
volvement at school as major determinants of children's academic outcomes. Coleman's conceptualization placed at its core action conditioned by social relations (particularly actions shaped by obligations, expectations, and norms) and viewed the positive functions of normative actions as key to shaping educational outcomes. We share the skepticism of others who question his fundamental assumption that all parents have similar goals concerning their children's education, that parents (should) wish and have the time to be involved, and that such involvement is universally appreciated (Dika and Singh 2002; Lareau 1989; Portes 1998).

Key to interpreting our empirical results are Bourdieu's $(1977,1980)$ earlier essays. In these, he articulated that social capital plays a key role in the reproduction of social inequalities (e.g., via benefits that accrue from membership in elite groups or organizations). Bordieu viewed people's ability to build social capital as inextricably linked to their habitus, roughly translated as "acquired, socially conditioned dispositions" (Bourdieu 1990, 12). Bourdieu stressed that habitus shapes people's potential and actual access to those social relations from which social capital can be derived.

Bourdieu's argument was originally designed to capture how class-specific cultural and organizational contexts in France serve social reproduction functions. Nonetheless, we can apply it to the German case because of its distinct social organization. In contrast to the United States, in Germany formal tracking starts early and remains pervasive; German secondary schools let out around lunch time and do not engage the majority of students in extracurricular activities such as sports or music. Organized sports, other voluntary associations (e.g., choirs), and religious congregations traditionally fulfill important communal functions by carrying the responsibility for afternoon youth activities. Group activities occur via voluntary associations such as the wellknown Turnvereine, which (like their functional U.S. equivalent, the YMCAs) offer programs for children and adults alike and which are places where parents of school-age children are likely to encounter other parents. Initially based on different status groups (Stände), they still provide a Gemeinschaft, or community of peers, albeit one potentially stratified along social and ethnic lines. They provide the organizational context in which habitus is enacted. But they also enable members to meet utilitarian goals by providing access to gatekeepers, institutional agents, and mentors, all of whom who can influence the flow of information and resources (Bader et al. 1983; Tönnies 1887 [1988]; Weber 1922 [1978]). Thus, adult ties to community groups serve as a key proxy for ethnic-based social capital, because "whom you know" determines "what you know" (Kao 2004).

The two conceptualizations are complementary, but they set different emphases. In contrast to Coleman, Bourdieu viewed social capital as marked not just by social relations per se but also by the access to information and other 
resources derived from those relationships (Portes 1998, 5, 12). He saw social capital as contingent on membership in a group/organization, especially institutionalized ties to entities associated with the dominant culture (Bourdieu 1980, 2; 1986, 248; Lamont and Lareau 1988). Our own contribution lies in highlighting how parental involvement in (voluntary) associations and with the dominant group affects the reproduction of educational inequalities by ethnic group.

Empirical literature.-How do researchers gauge social capital? Portes (1998) rightly warns that overextending the concept will reduce its heuristic value. Yet operationalization ranges from attitudinal measures such as parental aspirations (Downey 1995; Powell and Parcel 1999) to aggregate and even national-level indicators (e.g., on organization membership or neighborhood cohesion, see Putnam [2000] and Rury [2004]). To measure classic familybased social capital, researchers have employed a wide range of indicators regarding family structure, size, child-care arrangements, and parent-child communication/supervision (Bankston 2004; Goyette and Conchas 2002; Jungbauer-Gans 2004; Kao 1995; Shavit and Pierce 1991; Teachman et al. 1997). We use this research to guide our selection of family social capital measures. Regarding extrafamilial ties, we only include activities that link parents of students to other adults via informal or organizationally rooted activities. This enables us to test competing strands of social capital theory.

Coleman-inspired research usually regards social capital in a positive light. In general, parent-child communication improves educational aspirations, trajectories, and achievement (Baca et al. 1989; Carbonaro 1998; Downey 1995; Jungbauer-Gans 2004; Useem 1992). Parental involvement in children's education also affects educational outcomes, albeit in more complex ways. Typically U.S. researchers measure parental involvement via participation in PTArelated activities or parent-teacher meetings (Baker and Stevenson 1986; Coleman and Hoffer 1987; Ho and Willms 1996; Pong 1998; Useem 1992). We also know that parental involvement has ethnic and group-specific benefits for children's educational trajectories. While parental ties to teachers or schools generally improve children's academic achievement in the United States, such ties do not confer universal benefits but rather primarily benefit ethnic majority children (Lareau 1987, 1989; Lareau and Horvat 1999; Royster 2003). Related literature confirms that intergenerational dynamics and cultural practices shape school performance. Especially among immigrants, parental acculturation (including host-language skills) and acquisition of mainstream cultural capital influence children's academic achievement (Bankston and Zhou 1995; De Jong 1988; Jungbauer-Gans 2004; Kalmijn and Kraaykamp 1996; Korte 1990; Rumberger and Larson 1998; Stanton-Salazar and Dornbusch 1995; Warren 1996). ${ }^{3}$

Moreover, some networks are known to have adverse effects. As the differential 
association literature suggests, closely knit peer group ties among children can be negatively related to educational outcomes (Crosnoe et al. 2003; Goyette and Conchas 2002). Similarly, parental ties to peers and dense ties with family members can also have a negative impact (Büchel and Duncan 1998), especially for immigrants (Rumbaut 1997). Social closure among parents may create opposite effects on academic achievement, depending on institutional context (Morgan and Sorensen 1999). Our contribution lies in an explicit comparison of how these different forms of parental social capital shape educational trajectories for immigrant versus indigenous majority students.

Only a few German studies have examined the relationship between social capital and educational outcomes or have analyzed ethnic patterns. Instead, most German research continues to examine cohort- and class-based intergenerational attainment patterns. When examining ethnic patterns, studies tend to concentrate on the experience of Turks, who constitute Germany's largest ethnic group. For instance, Leenen et al.'s (1990) qualitative study shows that Turkish parents in Germany strongly rely on teacher recommendations regarding their children's track placement. Moreover, traditional gender norms in Turkish families disproportionately decrease parental aspirations and the school performance of girls (Alamdar-Niemann et al. 1991; Phalet and Schonpflug 2001). Other qualitative work suggests that Turkish adolescents face a Catch 22. The more independent Turkish adolescents are from their families, especially regarding traditional cultural norms, the better they perform in German schools. But in doing so, they risk fundamental intergenerational conflicts, which many teens find difficult to manage (Leenen et al. 1990). Thus, as Nauck et al. (1998) argue, intrafamilial and extrafamilial ties may serve very different purposes: among German Turks, family ties help first-generation immigrants, while extrafamilial ties are more important for the second generation. Our analyses include a more heterogeneous sample of immigrants in Germany, many of whom live there in the second or third generation (Kao 1995).

In addition, Büchel and associates note that parents engage in some extrafamilial activities together with each other (e.g., socializing, helping family), while other parental activities appear to be complementary and to occur in gender-specific ways. They find that parents' active sports participation has a positive effect on children's track placement, as does mothers' involvement in political activities (Büchel and Duncan 1998; Büchel and Wagner 2000-2001). Our article clearly builds on their work, but we extend these analyses by examining how community-based, organization-embedded parental ties create ethnic-specific effects in the track placement patterns of German and nonGerman students. This set of earlier findings led us to Bourdieu's work, which suggests that organization- and community-based forms of parental social capital are particularly important for the track placement of underprivileged groups. 


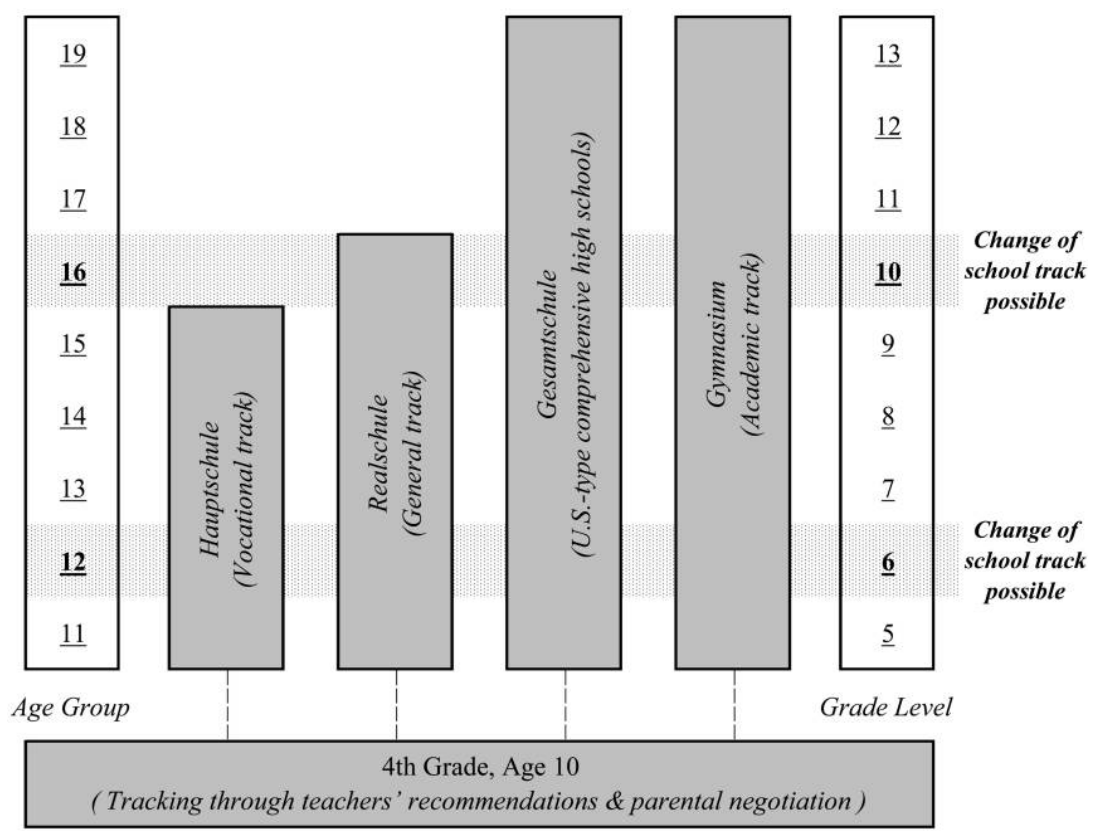

FIG. 1.-School track system in Germany. Further details regarding the German educational system are available in Centre for Educational Research and Innovation, Education at a Glance: OECD Indicators (Paris: Organisation for Economic Co-operation and Development, 1995); Kai S. Cortina, Jürgen Baumert, Achim Leschinsky, Karl Ulrich Mayer, and Luitgard Trommer, eds., Das Bildungswesen in der Bundesrepublik Deutschland: Strukturen und Entwicklungen im Überblick [The educational system of the Federal Republic of Germany: Overview of structures and trends], rororo-Sachbuch, vol. 61122 (Reinbek bei Hamburg: Rowohlt, 2003).

\section{Track Placement and Ethnic Inequality in Germany}

Most industrialized countries practice tracking in secondary schools, though specific tracking mechanisms differ cross-nationally. Turner (1960) used the term "external tracking" to describe the between-school differentiation common in Europe, exemplified by Germany's secondary school system (Shavit and Müller 1998). In Germany, external tracking practices lead virtually all students to attend different school types dependent on long-term occupational trajectories. This practice starts with the fifth-grade assignments to the Hauptschule (vocational), Realschule (general), or Gymnasium (academic). ${ }^{4}$ Grades 5 and 6 are generally considered a phase of "orientation" during which track placements can change. By the time students are 13 or 14 years old, track placement typically is fixed. ${ }^{5}$ Figure 1 provides a schematic overview of the German school system. 
Hauptschule students finish in nine years (the tenth year is optional). The Realschule requires 10 years, while the Gymnasium has $12-13$ years of schooling (depending on the state). Federal policy changes regarding mandatory school attendance through the ninth grade have facilitated an expansion in the Realschule sector rather than the Gymnasium (Müller and Haun 1994). Press coverage of the past two decades has stressed widely that the Hauptschule has become largely an educational and occupational dead end. It no longer serves as the best entry point for coveted apprenticeships, and it limits exposure to foreign languages and the hard sciences (Spiewak 2004). Yet mastery in these areas is a prerequisite for switching to the higher tracks, especially the Gymnasium, which regulates university access following a set of exit exams known as the Abitur.

Germany's federal system allocates jurisdiction over its educational structure, curricula, teacher accreditation, and funding to each state (Bundesland). While this creates state-specific idiosyncracies, clear tendencies prevail. In the fourth grade, teachers make nonbinding track placement recommendations. ${ }^{6}$ In contrast to the situation in the United States, parents in Germany have complete discretion in choosing a public secondary school, and they are not bound by place of residence. Public school principals must accept students with the appropriate track recommendation. Extensive and safe public transportation facilitates school choice, and urban schools are usually considered superior. Moreover, parental leverage has grown as competition for students has become more intense (a long-term result of low birth rates).

Finally, though parents are well aware of the three-tier system, decisions about placing children are based on a simpler typology. Parents choose whether to send a child to the Gymnasium or not or whether to send it to the Hauptschule or not (DeGraaf 1988; Kristen 2002). If they decide not to send the child to the Gymnasium, the Realschule (not the Hauptschule) becomes the next logical choice. Similarly, if the Hauptschule is deemed inappropriate, the Realschule usually becomes the first choice. Roughly one-fourth of secondary students attend the latter track, which offers the chance of transferring to the Gymnasium after the sixth grade or the tenth grade. The GSOEP sample distribution also reflects this figure (see table 1, across tracks, age, and ethnic group).

While the (dis)advantages of tracking continue to be a matter of debate (Arum and Shavit 1995; Hallinan 1992; Oakes 1985), most researchers agree that tracking has long-term effects on educational and occupational attainment and that it plays a key role in the reproduction of social inequalities (Müller and Haun 1994; Shavit and Blossfeld 1993; Shavit and Müller 1998; Yogev 1981). As countries become more ethnically diverse, tracking also reinforces inequalities along ethnic lines (Ayalon 1994; Baker et al. 1985; De Jong 1988; 
Shavit 1990). In Germany, pronounced ethnic differences in educational trajectories exist, whereby children of all immigrant groups (except Greeks) are more likely to attend lower tracks and to reach lower educational attainment as compared to ethnic Germans (Alba et al. 1994; Kristen 2002).

In general, Germans tend to send their children to higher tracks when the proportion of minorities in the local population increases. Some researchers argue that this practice leads to the inclusion of immigrants in the regular school system, albeit in a way that benefits children of German background. Others maintain that it is the leading cause of overrepresentation of minorities in the lowest track (Baker et al. 1985; Baker and Lenhardt 1988; Kornmann and Schnattinger 1989). Most important for our study, the type of school attended shapes parents' involvement in children's education (Oswald et al. 1988) and the diffusion of information and expertise (Frank et al. 2004).

The GSOEP data in table 1 show that ethnic minorities are disproportionately placed in lower tracks. This dovetails findings from other crossnational studies (Ayalon 1994; Shavit and Blossfeld 1993; Shavit and Müller 1998). We know that immigrant children in Germany, as elsewhere, are underrepresented in the academic track and that they disproportionately attend vocational schools (Alba et al. 1994; Baca et al. 1989; Baker et al. 1985; Büchel and Wagner 1996; Faist 1993; Malhotra 1985; Nauck et al. 1998). Yet the factors producing these ethnic tracking patterns remain unexamined. ${ }^{7}$

This composite picture suggests that parental social capital may play a key role for track placement outcomes. But which types of social capital affect track placement, and do similar effects exist across ethnic groups? Focusing on Germany to examine this issue allows us to test the generalizability of existing social capital explanations in a country whose educational system differs greatly from that of the United States but that also shares important similarities. Germany has absorbed more immigrants than any other European country since World War II, and it continues to do so. It relies on low-wage workers, especially those who have come from Turkey and Southern Europe. Turks constitute the largest and most visible immigrant group, and they hold a social position comparable to that of Mexicans in the United States. Children of "guestworkers" are the least likely to attend universities or to enter highstatus occupations, where secondary diplomas serve as a screening device for desirable apprenticeships. As competition for apprenticeships has increased, students from the lowest track have been squeezed out of the dual system and have been unable to enter the primary labor market. Even second- and thirdgeneration German Turks are more likely than other immigrants to experience teenage unemployment and to pursue occupations with little income potential (Esser 1990; Faist 1993; Kornmann and Schnattinger 1989; Müller and Haun 1994). 


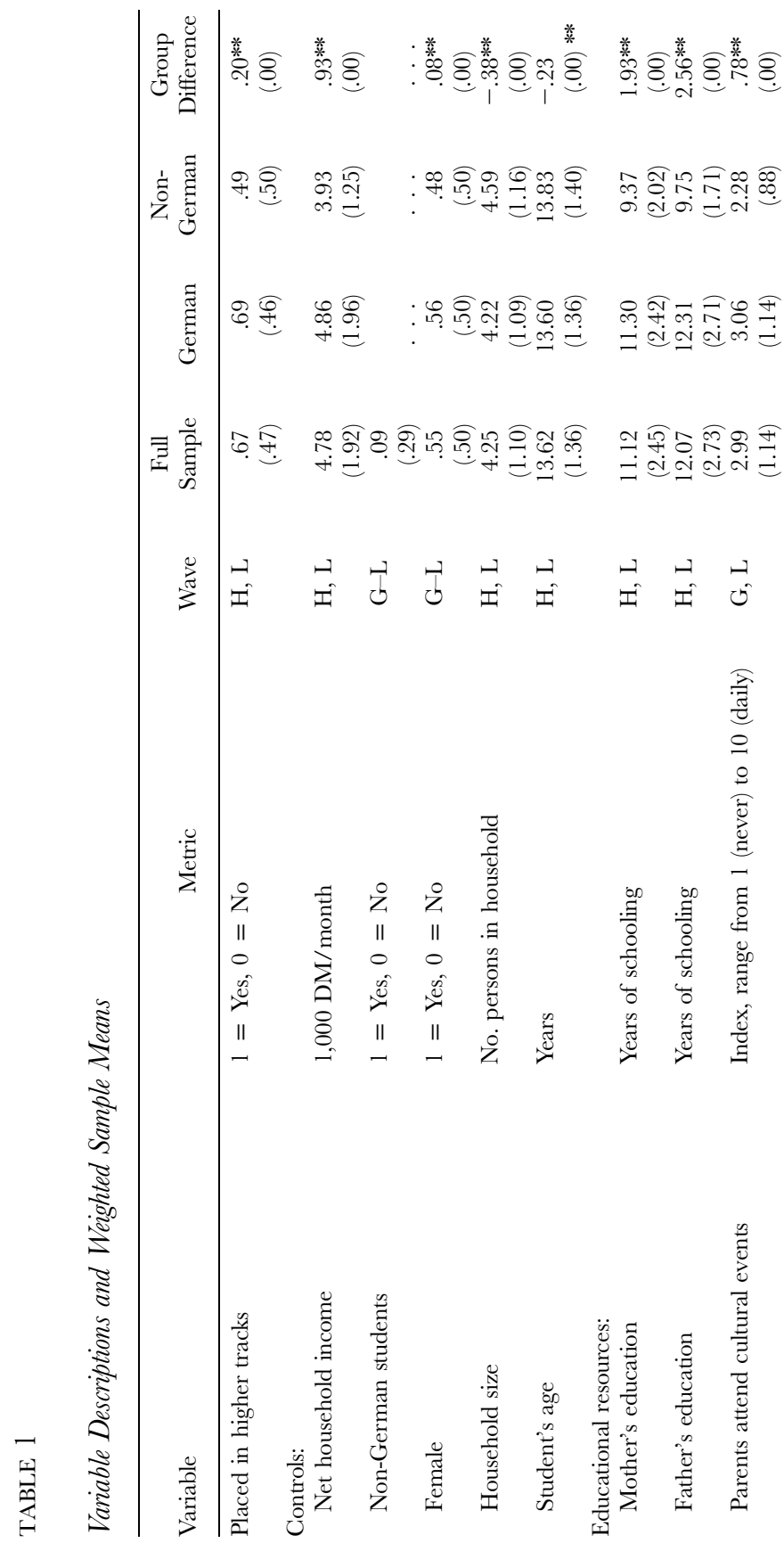




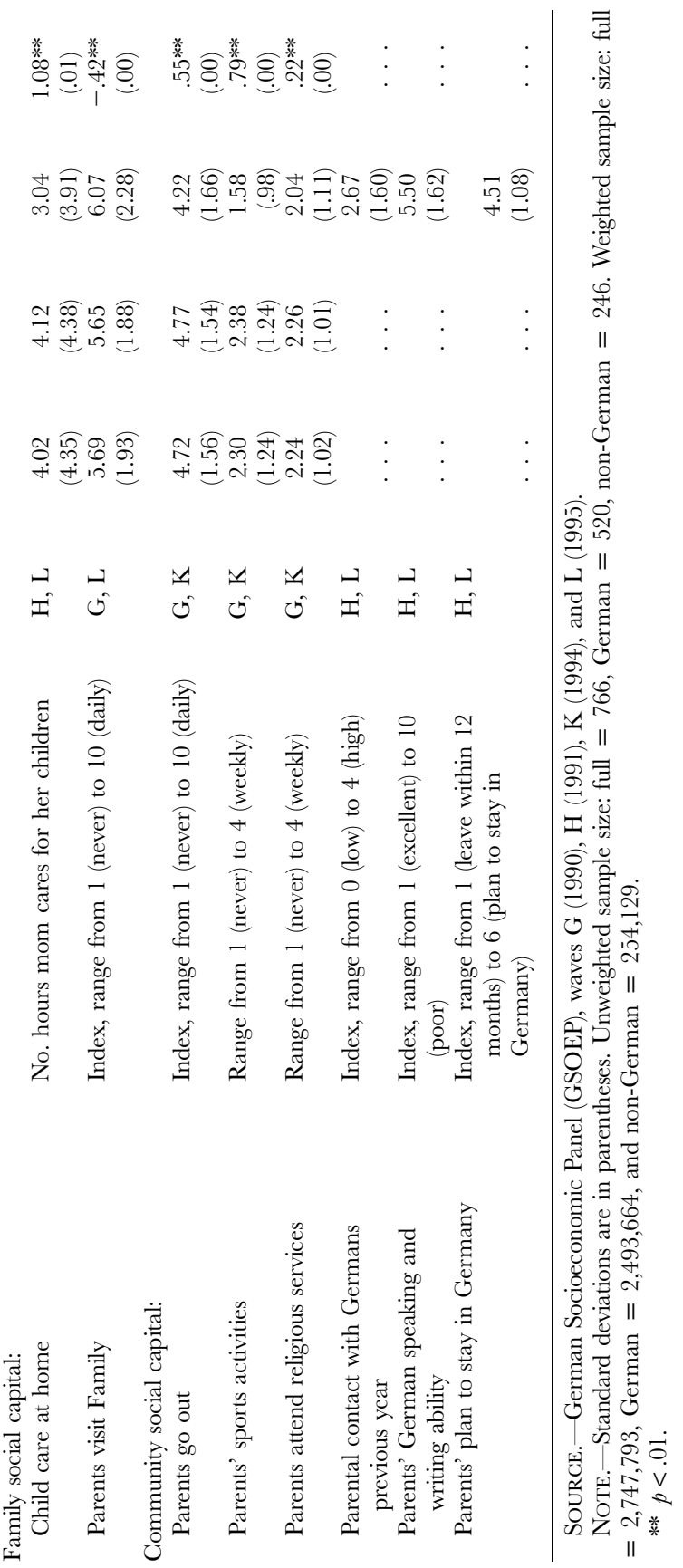




\section{Summary and Hypotheses}

The literature suggests that we should not rely on the U.S.-based empirical literature to generalize about the mechanisms through which different forms of social capital operate in other countries. Instead, social capital should have contextually (i.e., country- and group-) specific effects on educational outcomes. We focus on Germany because it differs markedly from the United States in the social organization of schooling and the extracurricular/leisure activities of adults and children. Substantively, Germany provides an ideal case study because it combines one of the most stringent tracking systems with one of the largest immigrant populations in Europe. Yet, despite these fundamental differences, schools still produce ethnically specific patterns similar to those of the United States, placing minorities at a distinct educational disadvantage.

Our analyses focus on how parental social capital creates ethnically specific effects on German and non-German students' educational trajectories. Drawing on competing strands of social capital theory, we examine three types of parental social ties: intrafamilial ties, informal extrafamilial social ties, and community- or organization-based extrafamilial ties. According to Coleman, strong primary ties - such as parental involvement with children and family ties - should improve students' educational outcomes, though Rumbaut (1997) suggests that this strategy does not work for immigrants in the United States.

Regarding extrafamilial social capital, our interest lies primarily in disentangling the ethnically specific effects of informal networks and formal (organizationally rooted) ties among adults. Again, Coleman's normative framework creates expectations that adult peer networks carry the greatest benefit. In contrast, Bourdieu's framework stresses that contact with community leaders and institutional agents, most likely found in the dominant (ethnic majority) group, forms a key manifestation of social capital. We expect that non-German parents are less likely than German parents to develop informal social ties with ethnic peers who are familiar with, and have access to, the German educational system. Consequently, their socializing activities tend to reduce involvement in their children's education and should have a detrimental effect on the track placement of non-German students. As for organizationally based social ties, we expect that Germans benefit more than non-Germans from their parents' involvement in voluntary associations, particularly via sports activities.

We also include three measures of parental acculturation for non-German families. First, forming stable social ties and becoming involved in the German community depend on the amount of time that will be spent in the host culture, and we expect the intended length of stay in Germany to have a positive effect on non-German students' track placement (Seifert 1997). Sec- 
ond, just as family ties provide an important support network, we should view immigrants' ties to Germans (members of the dominant group) as a proxy for parental social capital (Bourdieu 1980; Esser 1990). Research on Mexican immigrants in the United States reveals that parents are "generally unaware of their rights and obligations as parents in the U.S. school system" (Baca et al. 1989, 19). By extension, German acquaintances might help immigrant parents negotiate the German school system by serving either as sources of information or as mediators between parents and teachers. Related research suggests that such "weak ties" - rather than the strong ties that are typical of tightly knit homogeneous groups - have a positive impact on social mobility (Granovetter 1983; Lin 1999; Portes and Sensenbrenner 1993; Wong 1988). Thus, we expect a positive relationship between interethnic ties among adults and the likelihood that immigrant children attend one of the higher tracks. Finally, fluency in the host language has a consistent, positive effect on immigrant educational outcomes in the United States (Bankston and Zhou 1995; Kao 1995; Portes 1998; Stanton-Salazar and Dornbusch 1995). Prior research on Germany, however, has produced mixed results, suggesting positive or nonsignificant effects for German language ability (Büchel and Wagner 1996).

\section{Data and Method}

\section{Data and Variables}

The GSOEP is one of the most valuable and unique panel data sets available for a European country. First, it is known for remarkably high response rates and data quality. Second, it oversamples ethnic minorities and thus contains the largest repeated survey of immigrants in Germany. Third, it asks parents about their children's educational trajectory and allows us to operationalize parental social capital in ways that reflect different strands of social capital theory discussed above. Finally, it contains critical measures of immigrant acculturation, especially those pertaining to language skills and adult interethnic ties.

The GSOEP's main purpose is to follow the educational and occupational experiences of adults. This focus on adult mobility makes the GSOEP most comparable to the U.S.-based Panel Study of Income Dynamics, and it cannot easily be compared to the National Education Longitudinal Study (NELS). This means that the GSOEP has key drawbacks. It does not contain schoolor neighborhood-level information, making hierarchical modeling unfeasible. Moreover, available social capital indicators are not as detailed as we would like; this limits our own analyses and creates somewhat of a "black box" effect regarding the content of social ties. ${ }^{8}$ Most important, the GSOEP does not 
contain any indicators of children's prior academic achievement, which may cause readers to question the robustness of our findings. In our online methodological appendix (Cheng et al. 2007), we address this issue using a statistical procedure known as "impact threshold for a confounding variable" (ITCV), recently developed by Frank (2000). This procedure is designed to gauge the sensitivity of regression results to omitted variables. (For more details, see Cheng et al. [2007].) This online appendix contains a description of ITCV (Section $\mathrm{C}$ ) and also presents two tables and two figures that show that our results are indeed robust. The appendix Web site also contains a discussion of the results of supplemental analyses and alternative model fit statistics, modeling, and sampling techniques.

We limit analyses to West Germany because the minuscule proportion of immigrants in the former East Germany would skew comparisons. Following leading scholars who have used the GSOEP to examine track placement patterns, we extracted information on all children attending secondary school (GSOEP defines children as those who are $\leq$ age 16) and matched information on households, parents' background, and family and community ties. We base our analyses on an age-heterogeneous sample of track placement patterns among 11-16-year-olds from two different waves (1991 and 1995). We do so for three reasons: (1) Changes in immigration law and the influx of Eastern Europeans into Germany call for limiting the sample to postunification West Germany. (2) Expanding the age range to include 11-16-year-old secondary students maximizes the number of observations (especially for non-German students) and takes into account local/state variations in the timing and permeability of initial track placement. Separating the subsamples by four years also prevents individual students from being included more than once (we checked for accuracy). (3) Social capital questions were asked only in select waves, leading us to restrict analyses to the 1990-91 and 1994-95 waves.

In all, we analyze 766 secondary students, of whom 520 are ethnic Germans and 246 are non-Germans. We derive the dependent variable (track placement) from the 1991 and 1995 waves. When possible, we draw explanatory variables from two prior waves (1990 and 1994) rather than from the year the dependent variable is measured. While our sample construction cannot completely allay concerns about simultaneity and reverse causation, social capital theories (outlined above) focus explicitly on the directionality of these effects. Yet, given the cross-sectional flavor of our analyses, the strong statistical associations observed may or may not be causal. Using a person-level longitudinal weight constructed for the GSOEP, we report variable descriptions, weighted sample means, and standard deviations in table 2.

Track placement.-Following Alba et al. (1994), we code track placement zero if a student attends the Hauptschule, and one otherwise (Realschule, Gymnasium, Gesamtschule). Other researchers have coded the Gymnasium stu- 
TABLE 2

Nationality and Age Distribution of Students Attending Secondary School Tracks

\begin{tabular}{|c|c|c|c|c|c|}
\hline & & SECONDARY & SCHOOL TRACK & & \\
\hline & Hauptschule & Realschule & Gesamtschule & Gymnasium & TOTAL \\
\hline German: & & & & & \\
\hline $\begin{array}{l}\text { Number } \\
\text { (\% in parentheses) }\end{array}$ & $\begin{array}{l}166 \\
(31.9)\end{array}$ & $\begin{array}{l}141 \\
(27.1)\end{array}$ & $\begin{array}{l}7 \\
(1.4)\end{array}$ & $\begin{array}{l}206 \\
(39.6)\end{array}$ & $\begin{array}{l}520 \\
(100.0)\end{array}$ \\
\hline Number by age: & & & & & \\
\hline 11 & 7 & 6 & 0 & 10 & 23 \\
\hline 12 & 34 & 16 & 1 & 26 & 77 \\
\hline 13 & 52 & 38 & 0 & 61 & 151 \\
\hline 14 & 47 & 45 & 0 & 51 & 143 \\
\hline 15 & 18 & 15 & 0 & 24 & 57 \\
\hline 16 & 8 & 21 & 6 & 34 & 69 \\
\hline Non-German: & & & & & \\
\hline $\begin{array}{l}\text { Number } \\
\text { (\% in parentheses): }\end{array}$ & $\begin{array}{l}147 \\
(59.8)\end{array}$ & $\begin{array}{l}65 \\
(26.4)\end{array}$ & $\begin{array}{l}2 \\
(.8)\end{array}$ & $\begin{array}{l}32 \\
(13.0)\end{array}$ & $\begin{array}{l}246 \\
(100.0)\end{array}$ \\
\hline Number by age: & & & & & \\
\hline 11 & 12 & 3 & 1 & 1 & 17 \\
\hline 12 & 18 & 9 & 0 & 5 & 32 \\
\hline 13 & 36 & 17 & 0 & 9 & 62 \\
\hline 14 & 47 & 16 & 0 & 6 & 69 \\
\hline 15 & 26 & 8 & 0 & 4 & 38 \\
\hline 16 & 8 & 12 & 1 & 7 & 28 \\
\hline Number by country: & & & & & \\
\hline Turkey & 62 & 24 & 1 & 10 & 97 \\
\hline Former Yugoslavia & 27 & 17 & 0 & 8 & 52 \\
\hline Italy & 35 & 6 & 0 & 4 & 45 \\
\hline Other & 23 & 18 & 1 & 10 & 52 \\
\hline $\begin{array}{l}\text { Total sample } \\
\qquad(\text { German }+ \text { non-German): }\end{array}$ & & & & & \\
\hline $\begin{array}{l}\text { Number } \\
\text { (\% in parentheses })\end{array}$ & $\begin{array}{l}313 \\
(40.9)\end{array}$ & $\begin{array}{l}206 \\
(429.9\end{array}$ & $\begin{array}{l}9 \\
(1.2)\end{array}$ & $\begin{array}{l}238 \\
(31.1)\end{array}$ & $\begin{array}{l}766 \\
(100.0)\end{array}$ \\
\hline
\end{tabular}

SourCE.- German Socioeconomic Panel (GSOEP), waves H and L (1991 and 1995).

NOTE.-Hauptschule $=$ vocational track; Realschule $=$ general track; Gymnasium $=$ academic track; Gesamtschule $=$ U.S.-type comprehensive high schools. Pearson $\chi 2(d f=3)$ by nationality and school track $=70.1447(p=0.00)$. We included the Gesamtschule students among those attending higher tracks because these students have access to all tracks, including the Gymnasium. Excluding them (analyses not reported here) produced virtually the same results.

dents separately from all others (Büchel and Duncan 1998; Büchel et al. 1997; Büchel and Wagner 1996, 2000-2001). Descriptive statistics (table 1) show that this coding strategy works well for German students, who are tracked into three roughly equal groups. But only few non-Germans attend the Gymnasium, justifying a dichotomous dependent variable that separates the Hauptschule (vocational) students from all others in our analyses. Substantively, the Hauptschule versus non-Hauptschule contrast is also important because the Hauptschule is the only track that is regarded as a "dead-end" for future 
occupational and social mobility, and it does tend to enroll disproportionately more non-German students.

Parental social capital.- Several GSOEP measures capture the strength of family-based social relations. We also add several unorthodox social capital measures (not typically available in other data sets) that enable us to gauge the ethnically specific effects of parents' informal ties to peers plus activities that take place in organized settings in Germany via voluntary associations. This combination of measures captures the essence of social capital as action conditioned by social relations (Coleman) while also locating individual activities in people's habitus (Bourdieu). However, none of our measures provide direct indicators of parental aspirations regarding children's education or the content of network ties.

We include three types of parental social ties. First, to test Coleman's argument that family dynamics affect educational outcomes, we use two intrafamilial measures. Mothers' involvement in child care is measured by hours per week day mothers spend taking care of their children. ${ }^{9}$ U.S. studies often stress the importance of parent-child communication. Studies on other countries, however, suggest that family factors may have smaller effects on children's school outcomes than is typical for the United States (Broaded 1997). Table 2 suggests that German mothers spend significantly more time doing child care.

Parental visits to family members sums up the mothers' and the fathers' answers to the question "How often do you visit with family members or relatives?" ( 1 = never, $5=$ daily). This cumulative index measures the extent of parental ties to the extended family, which Shavit and Pierce (1991) have identified as crucial for ethnic minorities in Israel. Table 2 shows that nonGerman parents visit their relatives significantly more often than do German parents, indicating denser extended family ties among minorities (Bankston 2004; Kao 2004). ${ }^{10}$

Second, we use three proxies for extrafamilial parental ties, again using extant studies to guide our selection of measures. There is no functional equivalent for U.S.-style parent-teacher associations (PTAs) in Germany (nor are there quantitative data on parent-teacher communication; see Jungbauer-Gans 2004). But as informal relationships, rather than those rooted in primary groups, often prove more beneficial, such informal ties may be particularly important for disadvantaged groups (Bourdieu 1977; DiMaggio 1982; Granovetter 1983; Lin 1999; Putnam 2000; see also Bankston 2004; Royster 2003; Stanton-Salazar and Spina 2003; Teachman et al. 1997; and Wong 1988). Our index of informal parental socializing activities adds up both parents' answers to the question "How often do you go out to eat and drink?" ( $1=$ never, $5=$ daily). ${ }^{11}$ Two variables gauge organization-based parental involvement in the community: 
parents' participation in sports and attendance at religious services, both of which are measured as ordinal indices, ranging from 1 (never) to 4 (weekly). For these two variables, gender dynamics lead us to refrain from adding both parents' scores together. Instead, we follow Büchel and Wagner (2000-2001), using father's sports participation as the basis, supplemented with mother's participation whenever fathers' information is missing. Similarly, we use mother's attendance at religious services as the basis, supplementing father's involvement when mother's information is unavailable. Table 2 shows that German parents are more likely than non-Germans to go out to eat or to drink, to participate in sports activities, and to attend religious services.

Finally, we include three parental acculturation variables for non-Germans. We measure strength of interethnic ties by the extent of contact with Germans. This index sums responses of non-German fathers and mothers to questions about whether they visited and received visits from Germans during the previous year. Parents' German-language ability is a composite variable measuring mother's and father's speaking and writing skills, ranging from 1 (excellent) to 10 (poor). ${ }^{12}$ Plans to stay in Germany is a cumulative index of both parents' intention to return to their home country; it ranges from 2 (both parents plan to leave Germany within the year) to 6 (both parents plan to stay in Germany).

Controls and parental resources. - We include four controls for family and student characteristics. Monthly household income (net, in DM1,000) serves as a proxy for family SES and should be positively associated with track placement. We control for child's gender $(1=$ female) because of the ongoing debate about gender differences in children's educational outcomes (Carter and Wojtkewicz 2000; Gamoran and Mare 1989). Some researchers argue that parental resources are diluted as the number of children increases. We control for family size, measured as the number of people per household (Powell et al. 2004). To account for the heterogeneous age structure of our sample, we include child's age in all models.

In addition, we include three controls for parental cultural resources likely to affect track placement. We measure parental education separately, as father's and mother's years of schooling. Following Bourdieu and others (DiMaggio 1982; Downey 1995; Esser 1990; Kao 1995), who argue that children whose parents participate in cultural events are more likely to attend higher tracks, we measure parental participation in cultural events using a cumulative index based on father's and mother's response to the question "How often do you attend cultural events?" ( $1=$ never, $5=$ daily). Descriptives in table 2 parallel significant group differences reported in U.S. research: Germans have higher family income and parental education and smaller households and they are more likely to attend cultural events than immigrants (all $p$ 's $<.01$ ). 
Method

We use binary logistic regression to analyze the influence of parental social ties on students' track placement. In this commonly used method, a logistic distribution is assumed with $E(\varepsilon)=0$ and $\operatorname{Var}(\varepsilon)=\pi^{2} / 3$, leading to the equation:

$$
\operatorname{Pr}(y=1 \mid X)=\frac{\exp (\alpha+\beta X)}{1+\exp (\alpha+\beta X)}
$$

We report unit odds ratio changes for continuous and dichotomous variables and standard deviation odds ratio changes for ordinal variables (Long 1997). This facilitates interpreting the relative importance of ordinal parental social capital measures. Because we focus primarily on how parental social ties affect German and non-German students, we perform separate regression analyses for these two groups. Between-group significance tests regarding the effects of parental social ties are based on pooled analyses with interaction terms. (See our online methods appendix [Cheng et al. 2007] for more details.)

\section{Results}

Approximately one-fourth of secondary students in our sample attend the Realschule, regardless of ethnic background. Of the remaining students, 206 (40 percent) of Germans enroll in the academic track or the Gymnasium. In contrast, the majority of non-Germans (147, or 60 percent) go to the vocational Hauptschule. This ethnic pattern is statistically significant (Pearson $\chi^{2}$ test $(70.14$, $d f=3, p<.01))$ and is consistent with previous cross-national studies concerning the educational disadvantages of ethnic minority children. In supplementary analyses, we rigorously assessed the negative effect of non-German backgrounds on children's track placement. Results suggest that being non-German decreases the odds of attending higher tracks by 55 percent, net of students' family income, household size, gender, and age. In ancillary analyses, we found no nationalityspecific patterns; this was probably due to the small subsample size.

Our multivariate analyses, presented in table 3, proceed in stages. Model 1 presents the baseline of family background measures by ethnic group. Model 2 includes three additional measures of parental cultural resources. Model 3 assesses the group-specific effects of parental intrafamilial and extrafamilial social ties. Model 4 assesses the effects of crucial acculturation measures for the non-German subsample. 


\section{Group-Specific Results}

Logistic regression analyses (models 1 and 2 of table 3) confirm prior research showing strong class reproduction effects in Germany (Shavit and Müller 1998). As expected, children from families with higher incomes are more likely to attend a higher track, probably because SES itself serves as a proxy for the resources parents can invest into their children's school-based and extracurricular activities. In both groups, being female increases the odds of attending higher tracks, but the effect on non-German students is not statistically significant $(p>.1)$. This confirms cross-national analyses showing that, while gender inequalities in access to secondary education have declined, boys are more likely to be placed in the lowest track (Alba et al. 1994; Faist 1993; Müller and Haun 1994; Yogev 1981). Models 1 and 2 also show that, for German students, each additional household member decreases the odds of the student attending higher tracks by $19-25$ percent $((1-.75) \times 100$ percent $=25$ percent). For non-German students, the effects are even stronger, resulting in a 25-34 percent decrease in the odds of attending higher tracks $((1-.66) \times 100$ percent $=34$ percent $)$. Child's age is positively associated with attending higher tracks, but the effect is not statistically significant for non-German students.

At face value, these odds ratios suggest that genuine ethnic differences persist in track placement. But further examination of the base model indicates that, except for family income, these group differences are not statistically significant from one another $(p>.10)$. While those results stem partially from small (sub)samples and thus may not be conclusive (Cheng and Powell 2005), they set a baseline standard for assessing ethnically specific parental social capital effects on students' track placement.

Model 2 of table 3 adds three measures of parental resources to family background controls. Every additional year of education among mothers significantly increases the odds that German and non-German students attend nonvocational tracks, by 18 percent and 29 percent, respectively ((1.18 1) $\times 100$ percent $=18$ percent; $(1.29-1) \times 100$ percent $=29$ percent; $p<$ $.01)$. This difference between both coefficients retains statistical significance in model 3 when we add parental social ties. In contrast to the impact of mother's education on non-German students, father's education is more influential for German students (Alba et al. 1994; Müller and Haun 1994; Shavit and Blossfeld 1993; Shavit and Müller 1998). Analyses also suggest that parental participation in cultural activities has a positive effect on track placement for both student groups, at least before taking into account the influence of parental social ties. Note that descriptive statistics indicate overall lower levels of involvement in cultural activities among non-Germans (table 2).

In model 3, the effects of control and parental resource variables remain 


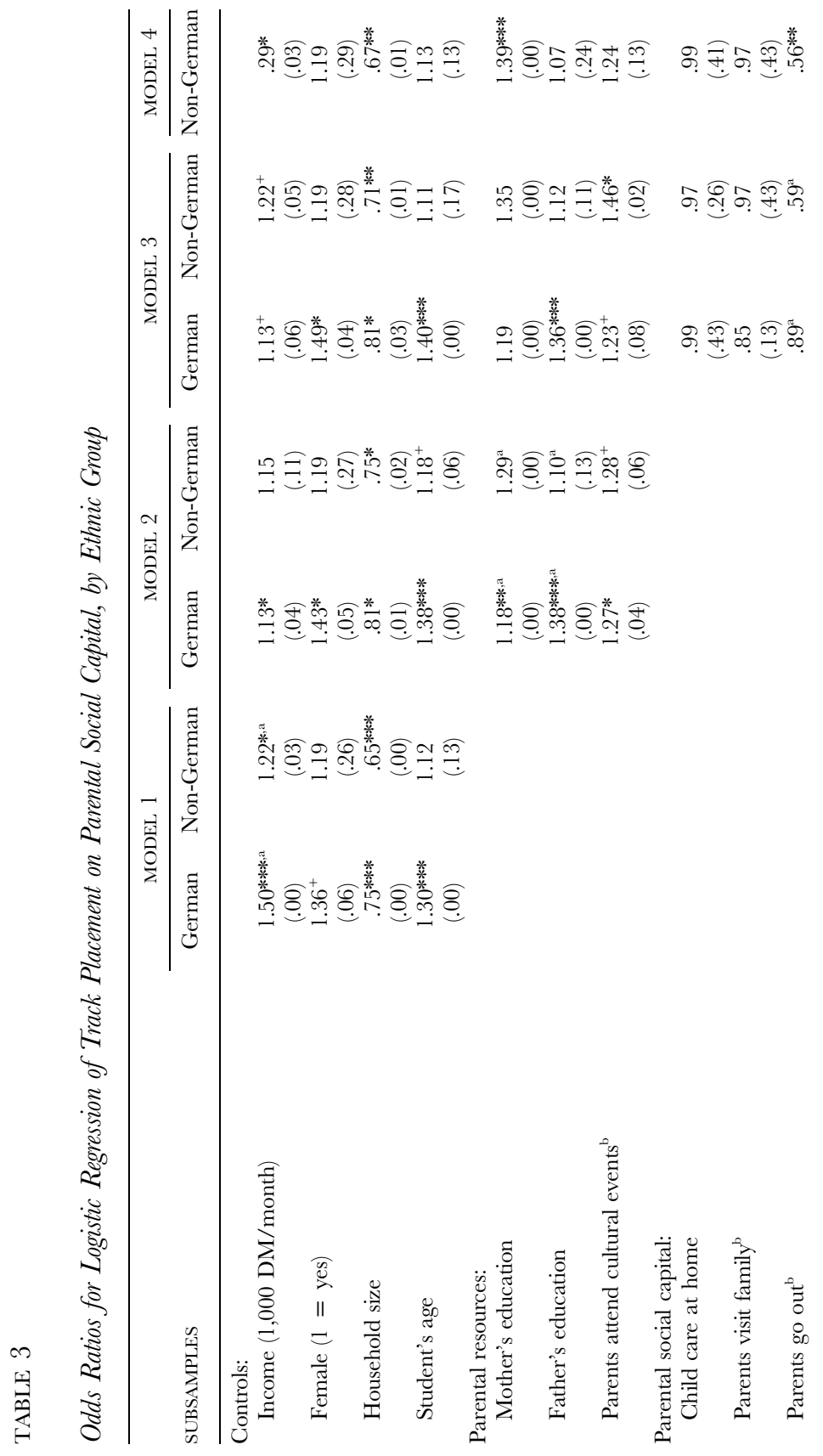




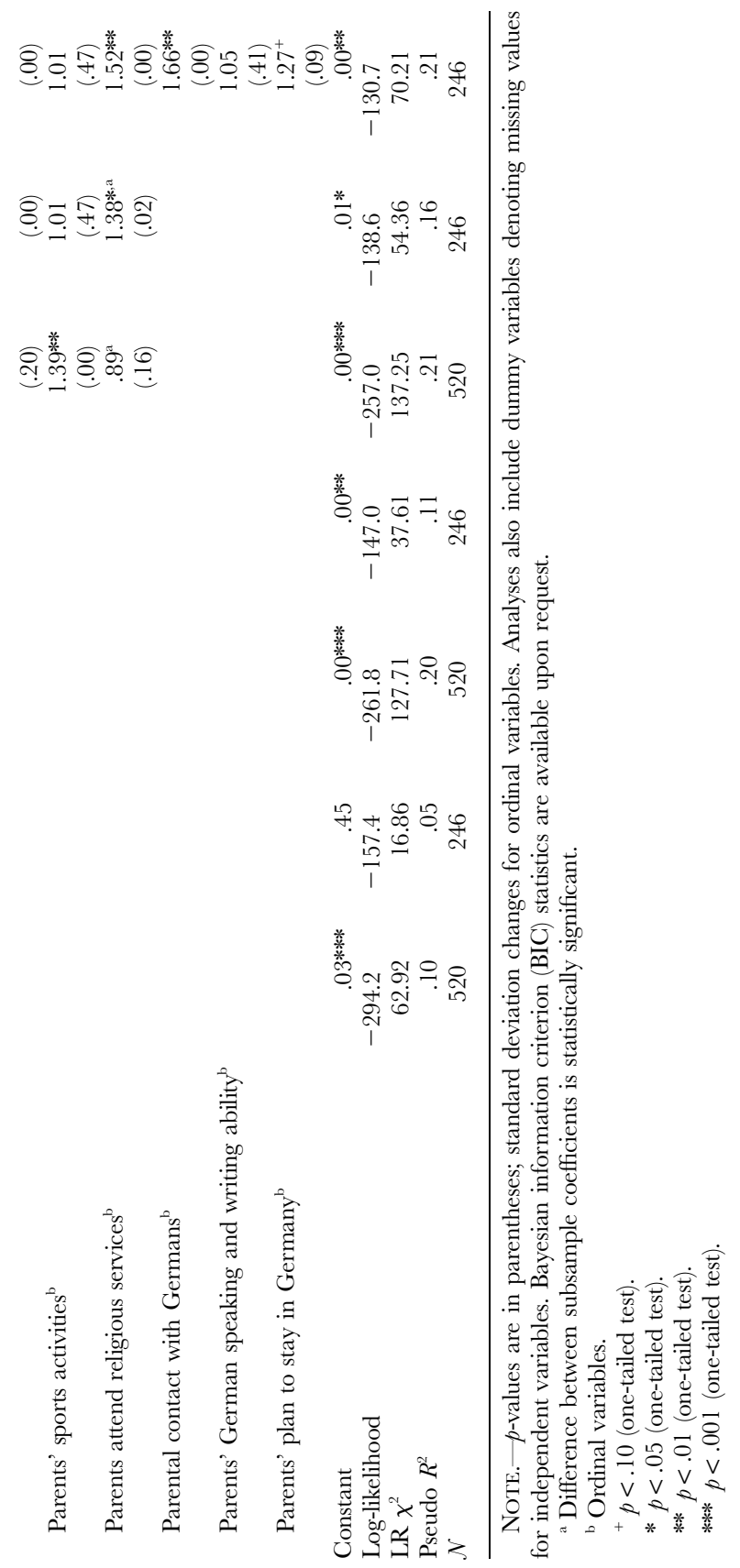


relatively stable even after we add parental social ties to the analysis. Of the five measures included, family-based ties - indicated here as mother's involvement in child care and parents' extended family contact - have no measurable impact on the track placement of German and non-German students, either singly or in combination. According to Coleman, close nuclear and extended family ties should have a positive effect on educational outcomes (also see Shavit and Pierce 1991), but our analyses for Germany do not substantiate that expectation. Of course, our measures of family-based ties may not perfectly capture all aspects of family social capital (though they capture the most meaningful measures available in the GSOEP and reflect the work of other scholars; see Büchel and Duncan [1998], Büchel et al. [1997], and Büchel and Wagner [1996, 2000-2001]). However, it is also possible that intrafamilial social capital simply plays a less significant role on educational outcomes in Germany than it does in the United States. Researchers have long tied individual-level educational goals and outcomes to structural parameters of the educational system (Bourdieu 1977; Broaded 1997; Buchmann and Dalton 2002; Oswald et al. 1988).

The second set of key findings appears in the differential effects of extrafamilial social ties, with strong, countervailing, group-specific effects on German and non-German students. Model fit statistics indicate that adding social capital variables proves particularly important for the non-German equation (improving model fit LR $\chi^{2}$ from 37.6 to 54.4), although the subsample size is less than half that of German students. Regarding individual odds ratios, informal ties to adult peers (parents going out to eat or to drink) produce selective negative effects, whereas students in each group seem to benefit from informal ties associated with parents' involvement in particular community-based organizations (i.e., religious services and sports activities). Thus, while challenging Coleman's faith in dense family-based ties, our results indicate that extrafamilial and organizationally based ties affect social reproduction - a notion endorsed by Coleman and Bourdieu as well as by the organization literature (Granovetter 1983).

First, parental socializing has a negative effect only on the odds of attending higher tracks among non-Germans, and the group difference is statistically significant. Why do the informal social activities of immigrant parents have this negative impact on their children's tracking? Social capital theories offer two interpretations. Coleman, who placed parent-child communication at the center of his analysis, might suggest that parents' time spent socializing with peers (most likely family and coethnics) reduces the time parents can spend with their children at home, possibly even exposing children to questionable adult role models. Although one might also infer from a cursory glance at the regression table that non-German parents cultivate such negative social ties with coethnics more intensively, German parents actually go out to eat and to drink with their peers 
more frequently than do non-Germans (see table 2). Yet parental socializing does not seem to affect German children's track placement negatively.

We argue that Bourdieu's perspective provides a more plausible interpretation (also Bankston 2004; Kao 2004; Stanton-Salazar and Dornbusch 1995). In Bourdieu's view, interpersonal ties constitute a means toward an end, where ties to the dominant group are key to obtaining information crucial for social mobility. In the best-case scenario (that of Germans), strong parent-peer ties have no significant negative impact because the closely knit, homogenous networks of Germans include other adults who are familiar with the educational system. In the worst-case scenario (that of non-Germans), homogenous networks reduce the opportunities for exchanging new and useful information. Immigrants would benefit from contact with "institutional agents," or even with informal mentors, who possess the best information about specific aspects of the dominant culture (e.g., how to negotiate track placement). Such gatekeepers are least likely to be found among non-German peers. Consequently, parent socializing with coethnic peers reinforces the already strong ties among non-German parents and may impede building ties to adults with information about the German school system.

Second, parents' participation in sports also produces ethnically specific effects on track placement. In contrast to Büchel's findings, our analyses suggest that this positive effect is limited to Germans. Because sports involvement in Germany typically takes place in an organizational context (Turnvereine), this implies that voluntary sports associations, a staple of German community and society for well over a century, still play a central role as conduits for social capital formation among German adults. This also points toward Bourdieu, who recognized that organizations associated with dominant groups provide access to gatekeepers and information critical to the reproduction of social inequalities. ${ }^{13}$

Third, parental attendance at religious services produces counterintuitive, ethnically specific effects. On the one hand, this variable apparently does not affect the odds of attending higher tracks among Germans. We believe that this may be related to the generally high level of secularization in German culture, where, unlike in the United States, Germans do not typically identify with local congregations or turn to religious leaders for help with school matters. Moreover, while parishes catering to Germans do offer youth activities, they rarely involve parents, and they are not school related.

On the other hand, increased parental attendance at religious services does improve track placement chances of non-Germans (regardless of nationality). At first glance, this finding seems at odds with Alamdar-Niemann et al. (1991), who show that religious-based gender norms decrease parental aspirations and school performance, particularly among Turkish girls. ${ }^{14}$ But most minorities in Germany, including Turks, are secular in orientation. Social capital theorists would note that even secular immigrants benefit from cultivating ties to ethnoreligious community groups, which (unlike informal socializing) may help 
cultivate ties with community leaders and institutional agents (Coleman and Hoffer 1987; Lareau 1987; Stanton-Salazar and Dornbusch 1995). We speculate that, like the secular sports associations for Germans, immigrant religious communities do serve a key social service function that enables immigrant parents to obtain resources and exchange critical information about the school system. To ascertain whether our explanation for these patterns is solid, we suggest that future studies examine the degree to which systematic differences exist in the educational/social services offered in German and non-German (often nonChristian) congregations. Unfortunately, the GSOEP does not contain sufficient information to answer this question.

Finally, model 4 of table 3 tests whether parental acculturation shapes nonGerman children's track placement. It confirms the social capital effects discussed above. Family-based involvement remains unrelated to students' track placement. Instead, extrafamilial parental social capital shapes track placement, with parental socializing showing a negative effect and ethnoreligious ties increasing the odds of immigrant students for attending higher tracks. Results overall suggest that parental acculturation also affects immigrant children's educational trajectories. ${ }^{15}$ Parents' German language ability had no statistically significant impact. Researchers have attributed this result to policy reforms in the 1980s, which reduced immigration from non-EU countries to a trickle and created long-term residents with adequate, relatively homogenous German language skills (Büchel and Wagner 1996; Seifert 1997). ${ }^{16}$ Of the remaining two measures, parental interethnic ties produce the largest effects, increasing the odds of children attending nonvocational tracks by 66 percent. The odds of non-German children attending higher tracks also increase (marginally) as parents indicate that they intend to stay in Germany over the medium to long term (Büchel and Wagner 1996). Both strands of social capital theory can explain why interethnic contact (rather than informal socializing with peers) benefits the trajectories of immigrant children. Coleman's normative interpretation suggests that identification with the host culture and assimilation into the mainstream will foster higher educational aspirations among immigrant parents, which, in turn, benefits their children. Bourdieu's social reproduction approach suggests that contact with gatekeepers (i.e., German adults who know how to navigate the educational system) can provide immigrant parents with crucial information on how to improve their children's track placement odds.

\section{Conclusion}

Most extant research is based on the assumption that social capital has universal, rather than group-specific, effects on educational outcomes around the world. We examine how parental social capital affects track placement in 
Germany in ethnically specific ways. We begin by outlining competing views of the role played by intrafamilial versus extrafamilial and organizationally embedded ties, rooted in work by Coleman, Bourdieu, and others (see Dika and Singh 2002). Our analyses provide no support for the argument that family-based social capital affects track placement for either Germans or nonGermans (also see Nauck et al. 1998). Our findings are robust and withstand rigorous tests designed to assess inherent data and modeling inadequacies (Frank's [2000] ITCV). They also echo a growing body of cross-national research showing that family-based social capital does not have a predictable and ubiquitous effect on educational outcomes (Broaded 1997; Büchel et al. 1997; Goyette and Conchas 2002; Jungbauer-Gans 2004; Kao 1995; Shavit and Pierce 1991).

Instead, we find that group-specific ties affect track placement, especially those tied to community-based organizations. It appears that Teachman et al. (1997) hit the mark when suggesting that some forms of social capital can have compensatory effects, especially for disadvantaged groups. On the one hand, we demonstrate that parental socializing with peers is inversely related to non-German children's educational trajectory. On the other hand, we show that German and non-German parents cultivate distinct community ties that affect their children's track placement. Parents' participation in secular voluntary associations (sports) improves German students' track placement. In contrast, parents' ties to ethnoreligious entities/activities seem to fulfill a comparable role for immigrants, as do interethnic ties with Germans. Thus, we find that gatekeepers for immigrants are likely to be found in two areas of social life: among leaders in their own ethnoreligious community and among Germans who can help immigrant parents navigate the educational system. Both kinds of ties help mitigate the reproduction of social inequalities through rigid tracking practices (Bourdieu 1980; Coleman 1988; Granovetter 1983; Lin 1999). In short, we propose that parental acculturation (i.e., familiarity with "the way the system works") achieved via ties to gatekeepers shapes children's track placement. ${ }^{17}$ More generally, our findings also echo arguments that the strongest network effects exist among individuals loosely knit within and across organizations (Granovetter 1983; Lin 1999; Portes and Sensenbrenner 1993).

Even sophisticated quantitative analyses have limitations. Are our findings unique to Germany? How does the institutional context, the social organization of schooling, shape the way in which specific social capital mechanisms affect social reproduction processes? Only explicitly comparative international studies can address this issue. Moreover, our social capital indicators are not as detailed as desirable, creating somewhat of a "black box" effect. We hope to stimulate new research directions, for example, investigation of the question, How do secular and religiously based community organizations facilitate the 
flow of information between rank-and-file members and gatekeepers? A growing number of qualitative studies prove insightful on this point (Crosnoe et al. 2003; Goyette and Conchas 2002; Royster 2003; Stanton-Salazar and Spina 2003). Yet, we still need more information about the content of such ties. For instance, do interethnic ties involve coworkers, parents of children's peers, teachers, or other gatekeepers? What do they talk about that makes these ties so instrumental? Answers would help inform the ongoing debate over the impact of how intergenerational closure affects educational outcomes in Europe and elsewhere (Carbonaro 1998, 1999; Morgan and Sorensen 1999; Stanton-Salazar and Dornbusch 1995).

Finally, while our analyses point to the crucial impact that adult interethnic friendships have on the track placement of immigrant children in Germany, future data collection efforts might ask whether interethnic ties also benefit the educational outcomes of ethnic majority children. This issue has farreaching policy implications as it can influence whether societies try to integrate immigrants into the dominant culture or foster intercultural exchange and network formation.

\section{Notes}

We, the three authors, contributed equally to this article, and our names are therefore listed in alphabetical order. This research was supported by grants to the third author: a postdoctoral fellowship from the National Academy of Education/Spencer Foundation, the Spencer Foundation's Small Grants Program, and NSF grant SES-9986586. We thank Robert Constantine and Eric Riles for data management. We thank Karl Alexander, Ken Frank, and Brian Powell for their feedback, and Martin Groeger, Sam Lucas, Ralph McNeal, Lauren Rauscher, and Li-Ling Yang for their support. Please direct all inquiries to Regina Werum, Department of Sociology, Emory University, Atlanta (GA) 30322. An unpublished online methodological appendix (Cheng, Martin, and Werum 2007) accompanying this article can be downloaded, or it may be obtained from any of the three authors.

1. For exceptions, see Büchel and Duncan (1998), Büchel et al. (1997), Büchel and Wagner (1996), Jungbauer-Gans (2004), Powell and Parcel (1999), Thorlindsson et al. (2000), and Wong (1998).

2. For reviews of how the social capital concept has evolved and of its widely acknowledged operationalization problems, see Bankston (2004), Dika and Singh (2002), Lamont and Lareau (1988), Lin (1999), and Portes (1998). We also believe that efforts to unpack the "black box of social capital" will prove more difficult for outcomeoriented, quantitative studies like ours. Instead, qualitative studies such as the work by Goyette and Conchas (2002), Lareau (1987, 1989, 1999), and Royster (2003) are ideally suited to demonstrate how different types of social capital lead to group-specific, differential outcomes. In contrast to social capital, cultural capital is typically defined as knowledge of elite cultural practices and norms, or as possession of elite cultural goods (Bourdieu 1979, 1986; Swartz 1977). Lamont and Lareau have adapted this concept for the United States, which possesses a "repertoire of high status cultural signals" 
(1988, 153) distinctive in the industrialized world. They also reiterate Bourdieu's (1986) observation that all forms of capital are interrelated, albeit not reducible to one another. While a thorough empirical analysis of this issue is beyond our scope, our analyses do include a proxy for parental cultural capital (attendance at cultural events).

3. Our definition of acculturation draws on Gordon (1964), who defined acculturation as equivalent to cultural or behavioral assimilation. It forms just one aspect of the assimilation process and differs from what he termed psychological assimilation. We regard this form of acculturation as a crucial precondition to acquiring social capital (i.e., meet the "right people" in the "right places").

4. Most pupils in Germany attend the three traditional, externally tracked school types. Comprehensive high schools modeled after U.S. high schools (Gesamtschule) have emerged recently but do not exist everywhere and remain largely absent from the East German secondary school system. Regional fluctuation in high school students attending comprehensive schools ranges from 2 percent in southern states to 25 percent in West Berlin (Oswald et al. 1988). Even students in these schools are encouraged to take the same level of courses to receive high school credentials oriented after the three traditional tracks. Only students who consistently take college preparatory classes and who stay 13 years qualify for entrance into the university system.

5. Although technically it is possible for this to be done, relatively few students switch tracks. About 10 percent of secondary students change tracks nowadays (Henz 1997). Among these, an equal proportion moves on to higher and lower tracks. But because track placement is not permanent and because some states and localities (e.g., Berlin) do not begin to track students until after the sixth grade, we examine track placements until age 16. Beyond this age, the only school track available is the Gymnasium (and the rare Gesamtschule). We discuss analyses of age-restricted (11-14-yearolds) and age-homogeneous subsamples in our unpublished online methodological appendix (Cheng et al. 2007).

6. Track recommendations officially are based on student academic performance during elementary school, though research shows that background criteria also play a role: parental cultural capital, rather than straightforward socioeconomic status (SES) background, structures decisions regarding children's transition to the highest track or the Gymnasium (DeGraaf 1988). These recommendations are shared - and often negotiated - with parents, who submit them to secondary school principals at the schools where they seek admission for their child. Despite their officially nonbinding character, enrolling a child in a particular track without the proper teacher recommendation remains difficult without proactive parental advocacy.

7. While the Hauptschule (lowest track) is increasingly viewed as a dead end, it is not clear whether immigrant parents are aware of this long-term trend. On the one hand, this trend has persisted for a long time, and the vast majority of immigrant parents included in our sample arrived before the immigration reforms in 1980. Thus one might expect immigrant parents in Germany (especially Turks and Italians) to be familiar with the hierarchical nature of the system and the effect of track placement on occupational and social mobility. Research by Alba et al. (1994), Phalet and Schonpflug (2001), and Kristen (2002) confirms this, noting that immigrant parents' preferences are also shaped by SES and gender norms. In other words, not all parents strive to place their children in the highest possible track. On the other hand, the GSOEP lacks data on parental aspirations for their children, putting an empirical examination of this issue beyond the scope of this article.

8. While we regret the relative paucity of social capital measures as typically employed in U.S. analyses using NELS and comparable data sets, we do strive to capture the essence of social capital as conceptualized by Coleman (actions by individuals, conditioned 


\section{Social Capital and Ethnic Tracking}

by relations) and Bourdieu (community and organizationally based access to institutional agents and bearers of information/resources), respectively. For instance, visits with extended family is a relatively general measure of family contact. However, research by Rumbaut (1997) and by Shavit and Pierce (1991) has shown that minorities rely heavily on such ties and are more likely to live with or in close proximity of extended family. In our case, most non-Germans have already lived in Germany for a number of years (a fact for which we control in analyses reported in footnotes), having arrived there via family-unification policies instituted in the 1970s and 1980s that made alternative immigration (e.g., labor recruitment) from outside the European Union virtually impossible. As for the absence of school-based parental involvement measures, the United States is an outlier regarding expectations of parental involvement in school. German schools let out in the early afternoon, and the non-school-based voluntary associations whose influence we try to capture here are the site where parents of school-age children are most likely to meet each other or institutional agents. In fact, detailed information about parental involvement at school is not even captured in more recent data sets such as the Programme for International Student Assessment (PISA) or Trends in International Mathematics and Science Study (TIMMS), which contain an otherwise excellent array of family social capital measures.

9. This general parental involvement measure does not let us ascertain the degree to which (non)German mothers assist children with homework. U.S. studies have shown mixed effects, though most suggest that parental help with homework is negatively related to educational achievement, possibly because parents only assist children with low grades (reverse causality). Our analyses confirm the directionality of said effect, though it never reaches statistical significance. This also may be due to the lack of specificity in the measure or to the fact that mothers doing a lot of child care (associated with small children) are less likely to have time to supervise the homework of the teenagers included in this study. The degree to which parental assistance with homework can either help or hurt achievement may also be group dependent (class, ethnicity). While many German mothers are likely to help with homework, immigrant moms may be less likely to do so as they do not necessarily understand either the language of instruction well enough or the educational system as such. Unfortunately, we cannot examine this issue in detail with the GSOEP data.

10. The smaller size of German households in our sample reflects the fact that the birth rate among ethnic Germans is lower than among immigrants. While this trend also limits access to extended family members, Germans in our sample actually report denser extended ties than do non-Germans (see table 2). Regardless of cultural norms about the salience of extended families, this reality may reflect the fact that immigrant families often live far away from the majority of their relatives. Unfortunately, this is the only available measure in the GSOEP gauging extended family ties.

11. As far as informal socializing is concerned, we are not the first to observe that adult leisure activities serve as a key means to exchange information, for better or for worse (see Büchel and Duncan [1998], Büchel et al. [1997], and Büchel and Wagner [1996, 2000-2001]); also see Tönnies [1887] and Weber [1922] regarding the German context). In Germany, adults, especially men, still spend evening leisure time at local neighborhood restaurants/bars/coffee houses. Thus informal socializing captures the potential for adult conversation, a feature identified as key by both Coleman and Bourdieu. In the German context, this type of adult socializing is most likely done without children. At ages $12-16$, the children in our sample are not likely to require a babysitter, and unlike in the United States, it is not uncommon for parents to leave young teens alone at home. Often this kind of parental socializing occurs in combination with (i.e., after) weekly sports or other regularly scheduled adult evening activities. It does not necessarily 
constitute a replacement for family dinners, as is the norm in the United States. In Germany, talking sports, politics, etc., with other adults (often same-sex and -ethnic groups) over some drinks is widely practiced, irrespective of social background. However, the homogeneity of these groups makes these encounters less likely to produce benefits such as the exchange of key information on the educational system. Unfortunately, the GSOEP does not contain detailed information on where adults meet to socialize or on what they talk about - the "black box" problem we addressed earlier. Our measures of religious participation and on interethnic ties among non-Germans also lack depth.

12. This social integration measure illustrates that social and cultural capital can overlap to a considerable degree and can, in fact, be converted (Bourdieu 1986; Lamont and Lareau 1988; Nauck et al. 1998).

13. Anecdotal evidence suggests that minority children in Germany are overrepresented on soccer teams, whereas German children are well represented in all sports activities, from tennis to gymnastics to ball games. However, no quantitative data exist in the GSOEP to examine or substantiate this speculative claim. To date, Büchel and Wagner's (2000-2001) GSOEP-based work remains one of the few peer-reviewed essays on this matter.

14. It is our understanding that the proportion of religious fundamentalists in the GSOEP sample, as in the population, remains too small to affect overall patterns in educational outcomes. Importantly, we view behavioral measures (e.g., attending religious activities) as conceptually distinct from attitudinal measures related to individual religiosity. Unfortunately, sample properties do not permit a meaningful breakdown of religious involvement by the immigrants' nationality.

15. Although reverse causality might be at work here (i.e., when non-Germans attend a higher track, their parents might experience increased exposure to Germans and then develop informal ties with them), Esser (1990) showed that school type has little influence on the existence of interethnic ties. Also note that, like other measures, our indicator of interethnic ties measures parents' contact with Germans during the previous year, minimizing the risk of reverse causality.

16. New mass immigration occurred only after reunification in 1990. This produced an influx of new immigrants from Eastern Europe, much of which is not reflected in our GSOEP data. Other researchers explain the lack of significant effects by pointing out that assessing language skills based on self-reports (as in GSOEP) may be less effective than more objectively obtained language skill measures.

17. Some researchers might conclude that interethnic ties signal the successful (psychological) assimilation of immigrant parents into the dominant culture, which they can translate into improved educational outcomes for their children. Yet, we are wary about interpreting our results as evidence that sheer assimilation into the dominant culture improves chances for immigrant educational success. Instead, we suggest that both ethnoreligious and interethnic social ties among adults serve complementary purposes.

\section{References}

Alamdar-Niemann, M., D. Bergs-Winkel, and H. Merkens. 1991. "Educational Conditions of Turkish Migrant Children in German Schools." Anthropology and Education Ouarterly 22 (2): 154-61.

Alba, Richard, Johann Handl, and Walter Müller. 1994. "Ethnische Ungleichheit 
im deutschen Bildungssystem." Kölner Zeitschrift für Soziologie und Sozialpsychologie 46 (2): 209-37.

Arum, Richard, and Yossi Shavit. 1995. "Secondary Vocational Education and the Transition from School to Work." Sociology of Education 68 (3): 187-204.

Ayalon, Hannah. 1994. "Monopolizing Knowledge? The Ethnic Composition and Curriculum of Israeli High Schools." Sociology of Education 67 (4): 264-78.

Baca, Reynaldo, Dexter Bryan, Clair McLean-Bardwell, and Francisco Gomez. 1989. "Mexican Immigration and the Port-of-Entry School." International Mioration Review 23 (1): 3-23.

Bader, Veit, Johannes Berger, Heiner Ganssmann, and Jost v.d. Knesebeck. 1983. Einfuihrung in die Gesellschaftstheorie. Frankfurt: Campus Verlag.

Baker, David, Yilmaz Esmer, Gero Lenhardt, and John Meyer. 1985. "Effects of Immigrant Workers on Educational Stratification in Germany." Sociology of Education 58 (4): 213-27.

Baker, David, and Gero Lenhardt. 1988. "Ausländerintegration, Schule und Staat." Kölner Zeitschrift für Soziologie und Sozialpsychologie 40 (1): 40-61.

Baker, David and David Stevenson. 1986. "Mothers' Strategies for Children's School Achievement: Managing the Transition to High School." Sociology of Education 59 (3): $156-66$.

Bankston, Carl. 2004. "Social Capital, Cultural Values, Immigration, and Academic Achievement." Sociology of Education 77 (2): 172-75.

Bankston, Carl, and Min Zhou. 1995. "Effects of Minority-Language Literacy on the Academic Achievement of Vietnamese Youth in New Orleans." Sociology of Education 68 (1): 1-17.

Bourdieu, Pierre. 1977. "Cultural Reproduction and Social Reproduction." In Power and Ideology in Education, ed. Jerome Karabel and A. H. Halsey. New York: Oxford University Press.

Bourdieu, Pierre. 1979. "Les trois états du capital culturel." Actes de la Récherche en Sciences Sociales 30 (30): 3-6.

Bourdieu, Pierre. 1980. "Le capital social: Notes provisoires." Actes de la Récherche en Sciences Sociales 31 (1): 2-3.

Bourdieu, Pierre. 1986. "The Forms of Capital." In Handbook of Theory and Research for the Sociology of Education, ed. John G. Richardson. New York: Greenwood.

Bourdieu, Pierre. 1990. In Other Words: Essays towards a Reflexive Sociology. Stanford, CA: Stanford University Press.

Broaded, C. Montgomery. 1997. "The Limits and Possibilities of Tracking: Some Evidence from Taiwan." Sociology of Education 70 (1): 36-53.

Büchel, Felix, and Greg Duncan. 1998. "Do Parents' Social Activities Promote Children's School Attainments?" Zournal of Marriage and the Family 60 (1): 95-108.

Büchel, Felix, Katharina Spiess, and Gert Wagner. 1997. "Bildungseffekte vorschulischer Kinderbetreuung." Kölner Zeitschrift für Soziologie und Sozialpsychologie 49 (3): 528-39.

Büchel, Felix, and Gert Wagner. 1996. "Soziale Differenzen der Bildungschancen in Westdeutschlan: Unter besonderer Berücksichtigung von Zuwandererkindern." In Lebenslagen in Wandel, ed. W. Zapf, J. Schupp, and R. Habich. Frankfurt: Campus Verlag.

Büchel, Felix, and Gert Wagner. 2000-2001. "Der Einfluss elterlichen Sporttreibens auf die Bildungsbeteiligung ihrer Kinder." Sportwissenschaft 30 (1): 40-53.

Buchmann, Claudia, and Ben Dalton. 2002. "Interpersonal Influences and Educational Aspirations in 12 Countries." Sociology of Education 75 (2): 99-112. 
Carbonaro, William. 1998. “A Little Help from My Friends' Parents: Intergenerational Closure and Educational Outcomes." Sociology of Education 71 (4): 295-313.

Carter, Rebecca, and Roger Wojtkiewicz. 2000. "Parental Involvement with Adolescents' Education: Do Daughters or Sons Get More Help?” Adolescence 35 (137): 29-44.

Cheng, Simon, Leslie Martin, and Regina E. Werum. 2007. Appendix accompanying "Adult Social Capital and Track Placement of Ethnic Groups in Germany," American Fournal of Education 114 (1), https://web.uconn.edu/simoncheng/AJE114-1.pdf.

Cheng, Simon, and Brian Powell. 2005. "Small Samples, Big Challenges: Studying Atypical Family Forms." Zournal of Marriage and Family 67 (4): 926-35.

Coleman, James. 1988. "Social Capital in the Creation of Human Capital." American fournal of Sociology 94 (July): S95-S120.

Coleman, James. 1990. Foundations of Social Theory. Cambridge, MA: Harvard University Press.

Coleman, James S., and Thomas Hoffer. 1987. Public and Private High Schools: The Impact of Communities. New York: Basic.

Crosnoe, Robert, Shannon Cavanagh, and Glen H. Elder Jr. 2003. "Adolescent Friendships as Academic Resources: The Intersection of Friendship, Race, and School Disadvantage." Sociological Perspectives 46 (3): 331-52.

DeGraaf, Paul. 1988. "Parents' Financial and Cultural Resources, Grades, and Transition to Secondary School in the Federal Republic of Germany." European Sociological Review 4 (3): 209-21.

De Jong, Mart. 1988. "Ethnic Origin and Educational Careers in Holland." Netherlands Fournal of Sociology 24:65-75.

Dika, Sandra, and Kusum Singh. 2002. "Applications of Social Capital in Educational Literature: A Critical Synthesis." Review of Educational Research 72 (1): 1-31.

DiMaggio, Paul. 1982. "Cultural Capital and School Success: The Impact of Status Culture Participation on the Grades of U.S. High School Students." American Sociological Review 47 (2): 189-201.

Downey, Douglas. 1995. "When Bigger Is Not Better: Family Size, Parental Resources, and Children's Educational Performance." American Sociological Review 60 (5): 746-61.

Esser, Hartmut. 1990. "Familienmigration und Schulkarriere ausländischer Kinder und Jugendlicher." In Generation und Identität: Theoretische und Empirische Beiträge zur Migrationssoziologie, ed. H. Esser and J. Friedrich. Band 97, Studien zur Sozialwissenschaft: Westdeutscher Verlag GmbH.

Faist, Thomas. 1993. "From School to Work: Public Policy and Underclass Formation among Young Turks in Germany during the 1980s." International Migration Review 27 (2): 306-31.

Frank, Kenneth A. 2000. "Impact of a Confounding Variable on a Regression Coefficient." Sociological Methods and Research 292 (2): 147-94.

Frank, Kenneth, Yong Zhao, and Kathryn Borman. 2004. "Social Capital and the Diffusion of Innovations within Organizations." Sociology of Education 77 (2): 172-83.

Gamoran, Adam, and Robert Mare. 1989. "Secondary School Tracking and Educational Inequality: Compensation, Reinforcement, or Neutrality?" American Fournal of Sociology 94 (5): 1146-83.

Gordon, Milton M. 1964. Assimilation in American Life. New York: Oxford University Press.

Goyette, Kimberly, and Gilberto Conchas. 2002. "Family and Non-Family Roots of Social Capital among Vietnamese and Mexican American Children." In Schooling and Social Capital in Diverse Cultures: Research in Sociology of Education, vol. 13, ed. Bruce Fuller and Emily Hannum. Oxford: Elsevier Science. 
Granovetter, Mark S. 1983. "The Strength of Weak Ties: A Network Theory Revisited." Sociological Theory 1:201-33.

Hallinan, Maureen. 1992. "The Organization of Students for Instruction in the Middle School." Sociology of Education 65 (April): 114-27.

Henz, Ursula. 1997. "Der Beitrag von Schulformwechseln zur Offenheit des allgemeinbildenden Schulsystems." Zeitschrift für Soziologie 26:52-69.

Ho, Esther Sui-Chu, and Douglas Willms. 1996. "Effects of Parental Involvement on Eighth-Grade Achievement." Sociologv of Education 69 (2): 126-41.

Jungbauer-Gans, Monika. 2004. "The Influence of Social and Cultural Capital on Reading Achievement: A Comparison of Germany, France and Switzerland Using PISA 2000 Data." Zeitschrift für Soziologie 33 (5): 375-97.

Kalmijn, Matthijs, and Gerbert Kraaykamp. 1996. "Race, Cultural Capital and Schooling: An Analysis of Trends in the United States." Sociology of Education 69 (1): $22-34$.

Kao, Grace. 1995. "Asian Americans as Model Minorities? A Look at Their Academic Performance." American Fournal of Education 103 (2): 121-59.

Kao, Grace. 2004. "Social Capital and Its Relevance to Minority and Immigrant Populations." Sociology of Education 77 (2): 172-83.

Kornmann, Reimer, and Christopher Schnattinger. 1989. "Sonderschulüberweisungen ausländischer Kinder, Bevölkerungsstruktur und Arbeitsmarktlage." Zeitschrift für Sozialisationsforschung und Erziehungssoziologie 9 (3): 195-203.

Korte, Elke. 1990. "Die Rückkehrorientierung im Eingliederungsprocess von Migrantenfamilien." In Generation und Identität: Theoretische und Empirische Beiträge zur Migrationssoziologie, ed. Hartmut Esser and Jürgen Friedrich. Frankfurt: Opladen.

Kristen, Cornelia. 2002. "Hauptschule, Realschule, oder Gymnasium? Ethnische Unterschiede am ersten Bildungsübergang." Kölner Zeitschrift für Soziologie und Sozialpsvchologie 54 (3): $534-52$.

Lamont, Michèle, and Annette Lareau. 1988. "Cultural Capital: Allusions, Gaps, and Glissandos in Recent Theoretical Developments." Sociological Theorv 6 (2): 153-68.

Lareau, Annette. 1987. "Social Class Differences in Family-School Relationships: The Importance of Cultural Capital." Sociology of Education 60 (2): 73-85.

Lareau, Annette. 1989. Home Advantage. London: Falmer.

Lareau, Annette, and Erin McNamara Horvat. 1999. "Moments of Social Inclusion and Exclusion: Race, Class, and Cultural Capital in Family-School Relationship." Sociology of Education 72 (1): 37-53.

Leenen, Wolf, Harald Grosch, and Ulrich Kreidt. 1990. "Bildungsverständnis, Plazierungsverhalten und Generationenkonflict in türkischen Migrantenfamilien." Zeitschrift für Pädagogik 36 (5): 753-71.

Lin, Nan. 1999. "Social Networks and Status Attainment." Annual Review of Sociology 25:467-87.

Long, Scott J. 1997. Regression Models for Categorical and Limited Dependent Variables. Thousand Oaks, CA: Sage.

Malhotra, M. K. 1985. "The Educational Problems of Children of Different Nationalities in West Germany." Ethnic and Racial Studies 8 (2): 291-309.

Morgan, Stephen, and Aage Sorensen. 1999. "Parental Networks, Social Closure, and Mathematics Learning: A Test of Coleman's Social Capital Explanation of School Effects." American Sociological Review 64 (5): 661-81.

Müller, Walter, and Dietmar Haun. 1994. "Bildungsungleichheit im Sozialen Wandel." Kölner Zeitschrift für Soziologie und Sozialpsychologie 46 (1): 1-42.

Nauck, Bernhard, Heike Diefenbach, and Kornelia Petri. 1998. "Intergenerationale 
Transmission von kulturellem Kapital unter Migrationsbedingungen." Zeitschrift für Pädagogik 44 (5): 701-22.

Oakes, Jeannie. 1985. Keeping Track: How Schools Structure Inequality. New Haven, CT: Yale University Press.

Oswald, Hans, David Baker, and David Stevenson. 1988. "School Charter and Parental Management in West Germany." Sociology of Education 61 (4): 255-65.

Parcel, Toby, and Mikaela Dufur. 2001. "Capital at Home and at School: Effects on Student Achievement.” Social Forces 79 (3): 881-912.

Phalet, Karen, and Ute Schonpflug. 2001. "Intergenerational Transmission in Turkish Immigrant Families." Journal of Comparative Family Studies 32 (4): 489-504.

Pong, Suet-ling. 1998. "The School Compositional Effect of Single Parenthood on Tenth-Grade Achievement." Sociology of Education 71 (1): 23-42.

Portes, Alejandro. 1998. "Social Capital: Its Origins and Applications in Modern Sociology." Annual Review of Sociology 24:1-25.

Portes, Alejandro, and Julia Sensenbrenner. 1993. "Embeddedness and Immigration: Notes on the Social Determinants of Economic Action." American fournal of Sociologv 98 (6): 1320-50.

Powell, Brian, Regina Werum, and Lala Steelman. 2004. "Macro Causes, Micro Effects: Linking Public Policy, Family Structure, and Educational Outcomes." In After the Bell: Family Background and Educational Success, ed. Dalton Conley and Karen Albright. London: Routledge.

Powell, Mary Ann, and Toby L. Parcel. 1999. "Parental Work, Family Size and Social Capital Effects on Early Adolescent Educational Outcomes: The United States and Great Britain Compared." Research in the Sociology of Work 7:1-30.

Putnam, Robert. 2000. Bowling Alone: The Collapse and Revival of American Communitv. New York: Simon \& Schuster.

Royster, Deidre. 2003. Race and the Invisible Hand: How White Networks Exclude Black Men from Blue-Collar Fobs. Berkeley: University of California Press.

Rumbaut, Rubén. 1997. "Ties That Bind: Immigration and Immigrant Families in the United States." In Immigration and the Family, ed. Alan Booth, Ann C. Crouter, and Nancy Landale. Mahwah, NJ: Erlbaum.

Rumberger, Russell W., and Katherine A. Larson. 1998. "Toward Explaining Differences in Educational Achievement among Mexican American Language-Minority Students." Sociology of Education 71 (1): 68-92.

Rury, John. 2004. "Social Capital and Secondary Schooling: Interurban Differences in American Teenage Enrollment Rates in 1950." American Fournal of Education 110 (4): 293-320.

Seifert, Wolfgang. 1997. "Occupational and Economic Mobility and Social Integration of Mediterranean Migrants in Germany." European Fournal of Population 13 (1): 1-16.

Shavit, Yossi. 1990. "Segregation, Tracking, and the Educational Attainment of Minorities: Arabs and Oriental Jews in Israel." American Sociological Review 55 (1): 115-26.

Shavit, Yossi, and Hans-Peter Blossfeld. 1993. Persistent Inequality: Changing Educational Attainment in Thirteen Countries. Boulder, CO: Westview.

Shavit, Yossi, and Walter Müller. 1998. From School to Work: A Comparative Study of Educational Qualifications and Occupational Destinations. Oxford: Clarendon.

Shavit, Yossi, and Jennifer Pierce. 1991. "Sibship Size and Educational Attainment in Nuclear and Extended Families: Arabs and Jews in Israel." American Sociological Review 56 (3): 321-30.

Spiewak, Martin. 2004. "Das Sorgenkind." Die Zeit, August 6, 13-16.

Stanton-Salazar, Ricardo, and Sanford Dornbusch. 1995. "Social Capital and the 
Reproduction of Inequality: Information Networks among Mexican-Origin High School Students." Sociology of Education 68 (2): 116-35.

Stanton-Salazar, Ricardo, and Stephanie Spina. 2003. "Informal Mentors and Role Models in the Lives of Urban Mexican-Origin Adolescents." Anthrobology and Education Ouarterly 34 (3): 231-54.

Stevenson, David, and David Baker. 1987. "The Family-School Relation and Child's School Performance." Child Develobment 58 (5): 1348-57.

Swartz, David. 1977. "Pierre Bourdieu: The Cultural Transmission of Social Inequality." Harvard Educational Reviewe 47 (4): 545-55.

Teachman, Jay, Kathleen Paasch, and Karen Garver. 1997. "Social Capital and the Generation of Human Capital." Social Forces 75 (4): 1343-59.

Thorlindsson, Thorolfur, Inga Sigfusdottir, and Stefan Jonsson. 2000. "Social Capital and Scholastic Achievement in an Icelandic Setting." Paper presented at the annual meeting of the American Sociological Association, Washington, DC, August.

Tönnies, Ferdinand. [1887] 1988. Gemeinschaft und Gesellschaft. Darmstadt: Wissenschaftliche Buchgesellschaft.

Turner, Ralph. 1960. "Sponsored and Contest Mobility and the School System." American Sociological Review 25 (6): 855-67.

Useem, Elizabeth. 1992. "Middle Schools and Math Groups: Parents' Involvement in Children's Placement." Sociology of Education 65 (4): 263-79.

Warren, John R. 1996. "Educational Inequality among White and Mexican-Origin Adolescents in the American Southwest: 1990." Sociology of Education 69 (2): 142-58.

Weber, Max. [1922] 1978. Economy and Society, ed. Guenther Roth and Claus Wittich. Berkeley: University of California Press.

Wong, Raymond. 1998. "Multidimensional Influences of Family Environment in Education: The Case of Socialist Czechoslovakia." Sociology of Education 71 (1): 1-22.

Yogev, Abraham. 1981. "Determinants of Early Educational Career in Israel: Further Evidence for the Sponsorship Thesis." Sociology of Education 54 (3): 181-94. 